Ind. Health, 1965, 3, 20.

\title{
EFFECT OF THE QUARTZ PARTICLES ON SOME CELLULAR METABOLISM
}

\author{
Kimiko KOSHI \\ National Institute of Industrial Health, Kizuki-Sumiyoshi, Kawasaki
}

(Received December 1, 1964)

\begin{abstract}
Some changes of metabolic activities of monocytes by phagocytosing alkaline-treated or ground quartz were studied. In the experimental condition in which the TTC reducing capacity of monocytes with alkaline-treated quartz was inhibited by $50 \%$ to control, the acid-soluble nucleotide in monocytes decreased by $40 \%$ to control. In the lactic acid production, the succinoxidase activity and DPNH-tetrazolium reducing capacity were unaffected in this condition, but they dropped with further increase of dust dose, and the lactic acid production was least effected by dusts among these cellular activities. The decrease of lactic acid production was not observed until the amounts of acid-soluble nucleotide in the monocytes with alkaline-treated quartz dropped below $30 \%$ of control.

From above results it was assumed that the first step of the toxic action of alkalinetreated quartz on monocytes was not an attack to respiratory and glycolytic systems of monocytes.
\end{abstract}

In the previous paper ${ }^{1)}$, in order to study the toxic action of the quartz particles on the intraperitoneal monocytes, some biochemical substances in the cells which were treated with two sorts of quartz particles with different surface were studied, And it was found that the amounts of amino acid, total nitrogen and nucleic acid in the cells decreased with the reduction of number of cells, whereas the decrease of acid-soluble nucleotide was rapid and remarkable; especially the decrease of the adenine nucleotide was marked in column chromatographic analysis.

In this report, the change of some metabolic activity of monocytes such as lactic acid production, the consumption of glucose, the succinoxidase activity and the INT (2-p-iodophenyl-3-nitrophenyl-tetrazolium chloride) reducing capacity in the monocytes with two sorts of quartz particles were studied in relation to the TTC (2, 3, 5-triphenyl tetrazolium chloride) reducing capacity and to the amouns of acid-soluble nucleotide in these monocytes.

\section{Materials}

The Cells and the Medium 


\section{EFFECT OF QUARTZ ON CELLULAR METABOLISM}

The cells obtained from intraperitoneal exsudate was induced in the male rats of Wister strain by the intraperitoneal injection of $4 \mathrm{ml}$. of sterile Tyrode's solution containing $0.001 \%$ glycogen. The exsudate obtained 2 days after the injection was washed with Tyrode's solution containing 8 units of heparin per $\mathrm{ml}$. and then the cells were separated from this heparinized solution by centrifugal separation at 1,500 r.p.m. for 5 minutes and washed twice with Tyrode's solution. The cells were suspended in Tyrode's solution. But, Tyrode's solution lacking glucose was used as medium for the analysis of pentose considering the interference of glucose to colour development by orcin method4).

\section{The Dusts}

The two sorts of quartz dust with different surface structure were used for this experiment. One was ground for 100 hours (designated as QI-100H) and the other was ground for 2 minutes and then treated with $10 \% \mathrm{NaOH}$ Solution (designated as LI2M). The sizes of these dusts were prepared to be 0.5 to $2 \mu$ or below $0.5 \mu$ in diameter by water sedimentation and centrifugation. The surface properties of these dusts were described in the previous paper 2 .

\section{Measuring Method}

\section{The TTC Reducing Capacity}

The method according to Marks and James3) was used. That is, the 2, 3, 5-triphenyl tetrazolium chloride and cystein were added to the cell suspension and then the cells were incubated for two hours at $37^{\circ} \mathrm{C}$. The reaction was stopped with acetone and the yield of formozan was determined electrophotometrically at $490 \mathrm{~m} \mu$.

\section{The Acid-soluble Nucleotide}

The cell suspension was centrifuged at 1500 r.p.m. for 10 minutes and the supernatant was removed. The cells was extracted with cold $0.6 \mathrm{~N}$ perchloric acid (PCA) at $0{ }^{\circ} \mathrm{C}$. And then the extracts were separated from the sediment by the centrifugation. These extracts were analyzed for pentose by the orcin method2).

\section{The Lactic Acid Production}

The cultures were deproteinized by the addition of $10 \%$ trichloroacetic acid. The lactic acid value in deproteinized fluid was measured by the method of Barker and Summerson4).

\section{The Succinoxidase Activity}

The succinoxidase activity was assayed manometrically by the technic as described by Schneider and Potter5).

\section{The Consumption of Glucose}

The cultures were deproteinized by the addition of $0.3 \mathrm{~N} \mathrm{Ba}(\mathrm{OH})_{2}$ and $5 \% \mathrm{ZnSO}_{4}$ and the glucose content of the deproteinized supernatant was measured by glucose oxidase activity (Glucostat, Worthington, Biochemical Co.)

\section{INT Reducing Capacity}

$0.4 \mathrm{ml}$. of $0.1 \%$ INT in Tyrode's solution was added to the culture. At the same 


\section{K. KOSHI}

time $0.1 \mathrm{ml}$. of $0.1 \mathrm{M}$ of $\mathrm{DPNH}$ or $\mathrm{Na}$ succinate were added as substrate. And then the cells were incubated for two hours at $37^{\circ} \mathrm{C}$. The reaction was stopped with acetone and the yield of formozan was determined electrophotometrically at $490 \mathrm{~m} \mu$.

\section{Experimental 1}

It was shown in the previous paper) that $200 \mu$ g of LI2M prepared to be 0.5 to $2 \mu$ in diameter was added to 5 million monocytes and after incubation for one hour at $37^{\circ} \mathrm{C}$, TTC reducing capacity of monocytes with LI2M was constantly inhibited by $50 \%$ to control.

Therefore, in the same ratios of dust doses to cell numbers, that is, 200, 400, 600, and 800 $\mu \mathrm{g}$ of LI2M were added to 5, 10, 15 and 20 million cells and after incubation for one hour TTC reducing capacity of each culture was determined. These results are shown in Fig.1. As seen in Fig 1, in the same ratio of dusts to cell numbers, TTC reducing capacity of monocytes was always inhibited by about $50 \%$ with LI2M independently with the dust dose and cell number.

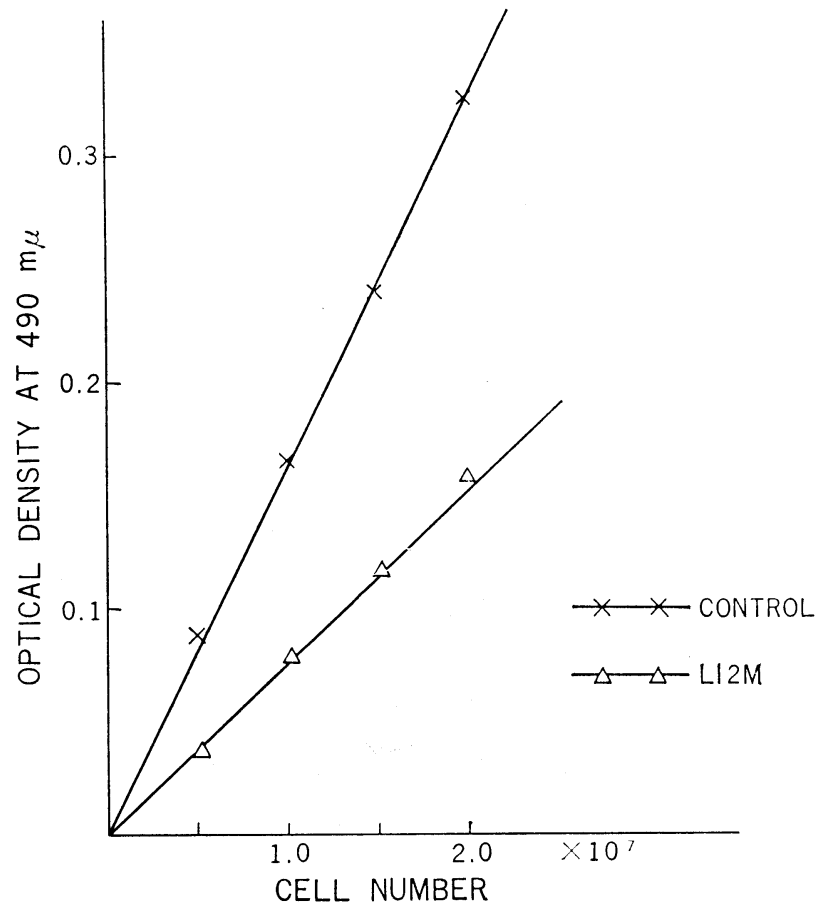

Fig. 1. TTC reducing capacity by rat monocyte with $\operatorname{LI} 2 \mathrm{M}(\triangle)$ and alone $(x)$

In this chapter, the above explained ratios of dust doses to cell number and incubation time were used as experimental conditions. The lactic acid production, the succinoxidase activity, the amounts of acid-soluble nucleotide, TTC reducing capacity and INT reducing capacity were determined under above experimental condition. 


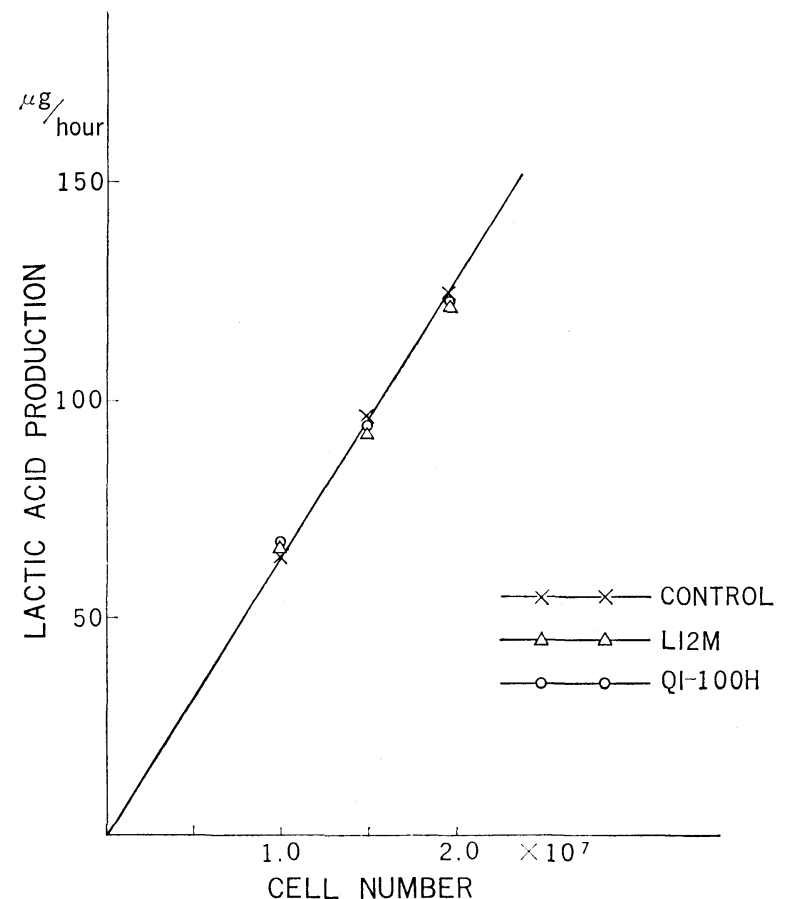

Fig. 2. Production of lactic acid by rat monocytes with $\operatorname{LI} 2 \mathrm{M}(\triangle), \mathrm{QI}-\mathrm{IOOH}(O)$ and alone $(x$

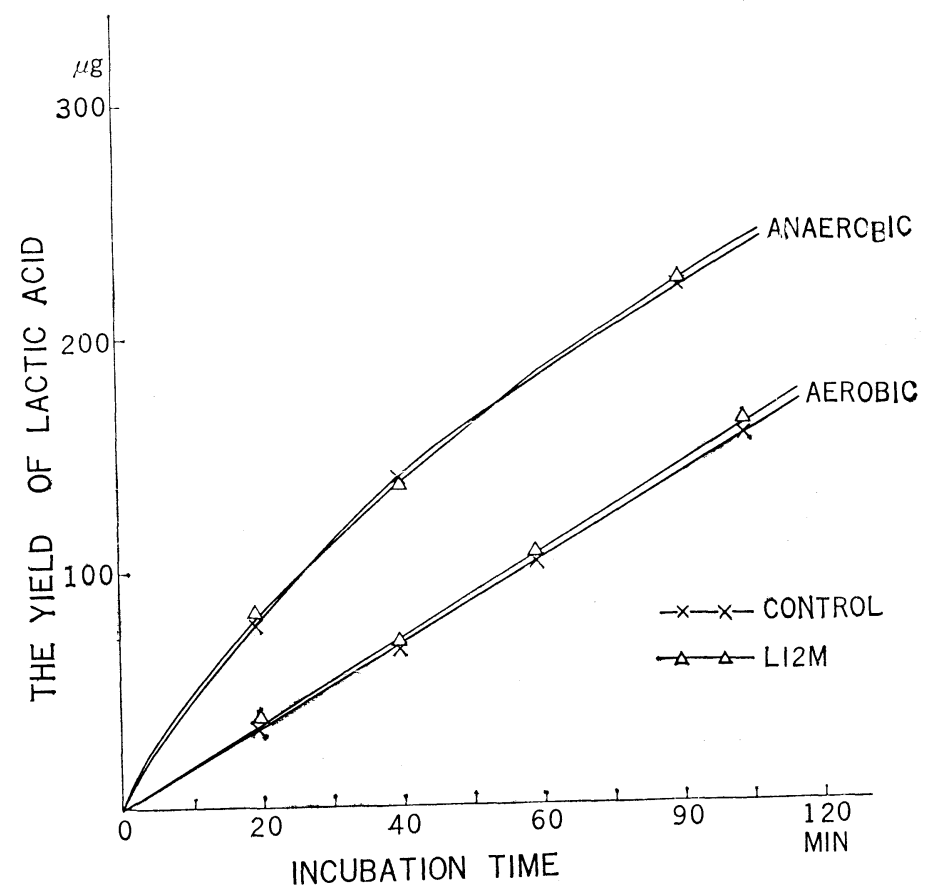

Fig. 3. Production of lactie acid by monocytes of rat incubated with $\operatorname{LI} 2 \mathrm{M}(\triangle)$ and without $\operatorname{dust}(x)$ under anaerobic and aerobic condition. 


\section{K. KOSHI}

\section{Lactic Acid Production}

400,600 , and $800 \mu \mathrm{g}$ of LI2M or QI- $100 \mathrm{H}$ were added to 10,15 , and 20 million cells respectively and these tubes were incubated for one hour at $37^{\circ} \mathrm{C}$. After incubation the cultures were deproteinized and then lactic acid of deproteinized fluid was determined. The results are shown in Fig 2. As shown in the figure, the lactic acid production of monocytes without dust increased with increasing cell number linearly. There were no noticeble differences of lactic acid production between cells with LI2M, QI-100H and control.

Then, $600 \mu \mathrm{g}$ of LI2M was added to 15 million monocytes and the cell-dust mixture incubated at $37^{\circ} \mathrm{C}$ for $20,40.60$ and 90 minutes under aerobic and anaerobic condition using Thunberg tube. After incubation lactic acid content in each culture was measured. As seen in Fig. 3, the yield of lactic acid was larger in the anaerobic condition than in the aerobic condition. The lactic acid production of the cells were not affected by the addition of LI2M until 120 minutes under these experimental condition.

\section{Succinoxidase Activity}

Eight hundred micrograms of LI2M or QI-100H were added into 20 million monocytes suspension and these mixtures were incubated for one hour at $37^{\circ} \mathrm{C}$. After incubation, 0.2 $\mathrm{ml}$ of $0.2 \mathrm{M} \mathrm{Na}$ succinate, $0.3 \mathrm{ml}$ of $4 \times 10^{-3} \mathrm{M} \mathrm{AlCl}, 0.3 \mathrm{ml}$ of $4 \times 10^{-3} \mathrm{M} \mathrm{CaCl}_{2}$ and 0.4 $\mathrm{ml}$ of $10^{-4} \mathrm{M}$ cytochrome $\mathrm{C}$ were added and the uptake of oxygen was measured by manometrically for 60 minutes. As seen in Fig. 4 the oxygen uptake of cells was not changed by the addition of LI2M, QI-100H.

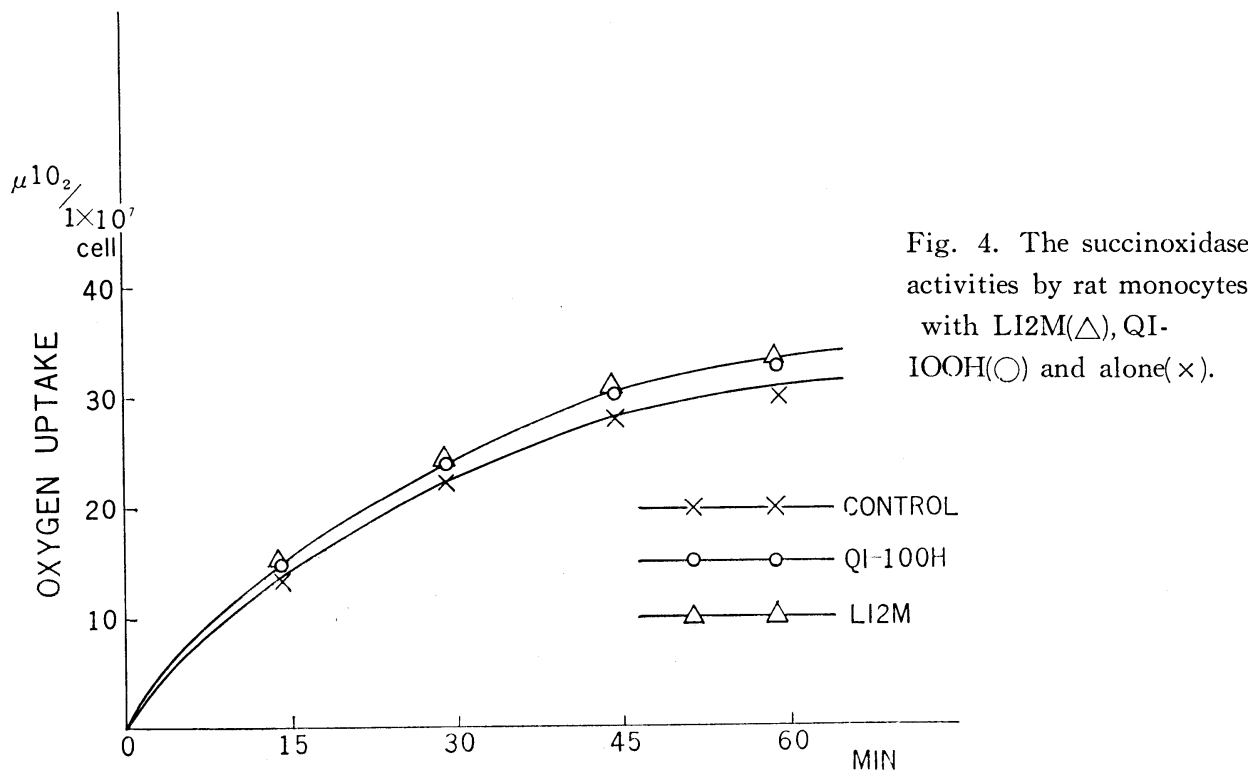

INT and TTC Reducing Capacities

Two hundred micrograms of LI2M or QI-100H were added to 5 million cells and cell- 


\section{EFFECT OF QUARTZ ON CELLULAR METABOLISM}

dust mixtures were incubated for one hour at $37^{\circ} \mathrm{C}$. After incubation TTC and INT reducing capacities of monocytes were measured using glucose, DPNH and succinate as substrates. As seen in Table 1, TTC reducing capacity of monocytes was inhibited most strongly by LI2M when glucose was used as substrate. INT reducing capacity of monocytes with LI2M was inhibited when substrate was not added. When DPNH or Succinate was used as substrates, TTC reducing capacity of monocytes was inhibited by LI2M, but INT reducing capacity was not. From above results the two sorts of tetrasolium may react to different biochemical process in monocytes. The detail of properties of two tetrazolium reducing capacities of monocytes will be described later in this journal.

Table 1. TTC and INT reducing capacities of monocytes with various subsrates.

\begin{tabular}{c|l|r|r|r}
\hline \multirow{2}{*}{$\begin{array}{c}\text { Sort of } \\
\text { tetrazolium }\end{array}$} & Substrate & \multicolumn{2}{|c|}{ Yield of formozam } & \multicolumn{2}{c}{\begin{tabular}{c} 
L12M \\
\cline { 3 - 5 }
\end{tabular}} & Control & L12M & control \\
\cline { 3 - 4 } T'TC & Endogenous & $6.0 \mu g$ & $4.0 \mu g$ & $66.6 \%$ \\
& Glucose & 20.0 & 10.3 & 51.5 \\
& DPNH & 12.0 & 9.5 & 79.1 \\
& Succinate & 11.5 & 8.5 & 74.0 \\
\hline \multirow{5}{*}{ IN'T } & Endogenous & 20.0 & 10.0 & 50.0 \\
& Glucose & 16.5 & 13.0 & 78.8 \\
& DPNH & 24.5 & 29.0 & 120.8 \\
& Succinate & 22.5 & 24.0 & 106.6 \\
\hline
\end{tabular}

\section{Experimental 2}

In the above experimental condition the TTC reducing capacity and the amounts of acidsoluble nucleotide are reduced by about 50 and $40 \%$ to control respectively. However, lactic acid production, succinoxidase activity, DPNH-INT reducing capacity and succinate-INT reducing capacity of monocytes were unaffected by LI2M or QL-100H. So, in this chapter, 400, $800,1200,1600,3200 \mu \mathrm{g}$ of LI2M or QI- $100 \mathrm{H}$ of $0.5 \mu$ to $2 \mu$ size were added to 10 million of monocytes and then each tube was incubated for one hour at $37^{\circ} \mathrm{C}$. After incubation the production of lactic acid, the consumption of glucose, DPNH-INT reducing capacity, succinoxidase activity, the amounts of acid-soluble nucleotide and TTC reducing capacity were measured by above described methods.

Results obtained with LI2M are shown in Fig.5. As seen in Fig. 5, the amounts of acid-soluble nucleotide and TTC reducing capacity of monocytes with LI2M were reduced linearly with increasing dust doses compared with those of controls. The production of lactic acid and the consumption of glucose decreased only by the addition of $3200 \mu \mathrm{g}$ of dusts in this condition. In this dust dose the amounts of acid-soluble nucleotide in monocytes was $27.5 \%$ of control.

The succinoxidase activity decreased by the addition of more than $800 \mu \mathrm{g}$ of LI2M and DPNH-INT reducing capacity was reduced by the addition of more than $1200 \mu \mathrm{g}$ of LI2M. 


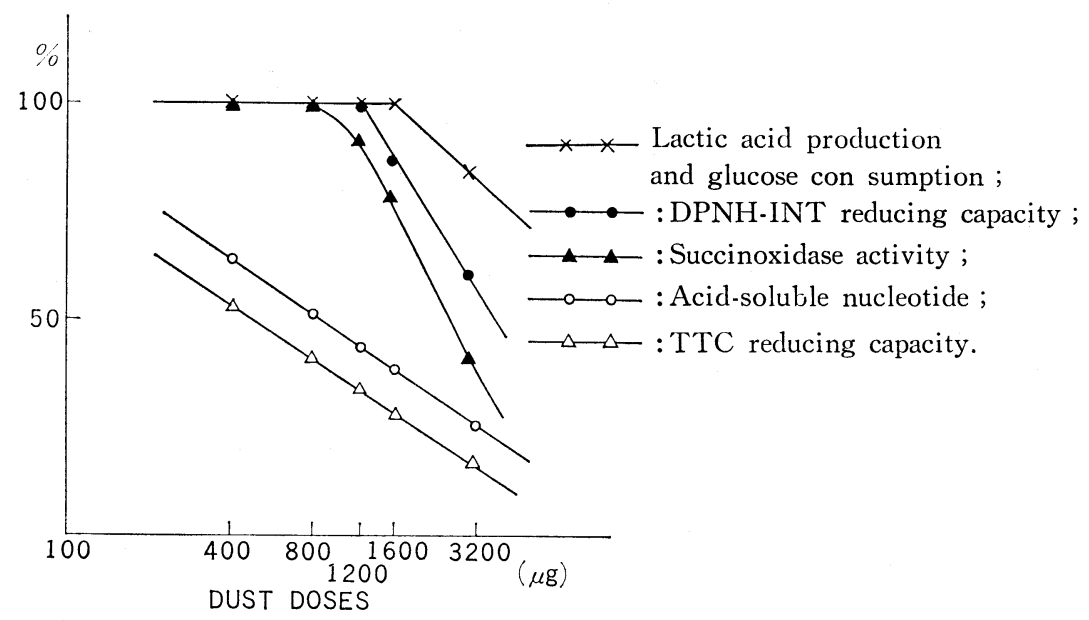

Fig. 5. The change of some cellular metabolism by the addition of LI2M prepared 0.5 to $2 \mu$ in diameter.

QI-100H had no inhibitory effect on these of the cell activities in the same doses as LI2M.

\section{EXPERIMENTAL 3}

It was reported in the previous paper ${ }^{7}$ that the toxic action of quartz particles was shown after phagocytosis of quartz particles by monocytes. In the case of addition of $3200 \mu \mathrm{g}$ of LI2M to 10 million monocytes, quartz particles are numerously observed out side of the cells microscopically. But, the decrease of lactic acid production and glucose consumption were caused by the addition of $3200 \mu \mathrm{g}$ of LI2M for the first time. Furthermore, it was

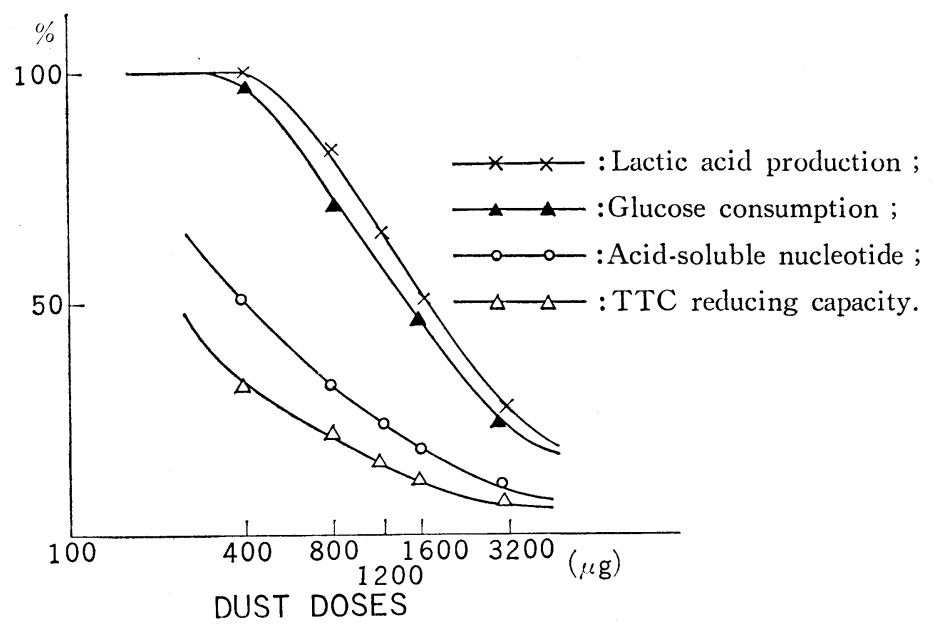

Fig. 6. The change of some cellular metabolism by the addition of L12M prepared below $0.5 \mu$ in diameter. 


\section{EFFECT OF QUARTZ ON CELLULAR METABOLISM}

shown in the previous paper ${ }^{8)}$ too that LI2M prepared below $0.5 \mu$ in diameter was more toxic than that of size of 0.5 to $2 \mu$. In this chapter, 400, 800, 1200, 1600, and $3200 \mu \mathrm{g}$ of LI2M or QI-100H prepared below $0.5 \mu$ in diameter were added to 10 million of monocytes respectively. And then these were incubated for one hour at $37^{\circ} \mathrm{C}$. After incubation, the amounts of lactic acid production, glucose consumption, acid-soluble nucleotide and TTC reducing capacity were determind. In the cells with QI-100H the each measured values by the addition of each dust doses were almost equal to those of controls. The results obtained from LI2M treated cells were shown in Fig 6. As seen in the figure the amount of nucleotide was reduced by $50 \%$ by the addition of $400 \mu \mathrm{g}$ of LI2M in comparision with that of control and this value by adding of $800 \mu \mathrm{g}$ was about $30 \%$ of control. The lactic acid production was not changed by $400 \mu \mathrm{g}$ of dust, but it decreased linearly with increasing dust doses by the addition of more than $800 \mu \mathrm{g}$ of LI2M. The tendency of decrease of the consumption of glucose was almost equal to that of the lactic acid production and TTC reducing capacity decreased similarly with nucleotide.

\section{Experimental 4}

In order to determine the relationship between the lactic acid production and the amounts of nucleotide, $400 \mu \mathrm{g}$ and $800 \mu \mathrm{g}$ of quartz particles of size below $0.5 \mu$ of LI2M and QI-100H were added to 10 million monocytes and these dust-cell mixtures were incubated for $0.5,1$, $1.5,2$ and 3 hours at $37^{\circ} \mathrm{C}$. After incubation, the amounts of nucleotide and lactic acid production were estimated respectively. The results were shown in Fig. 7. As seen in Fig. 7,

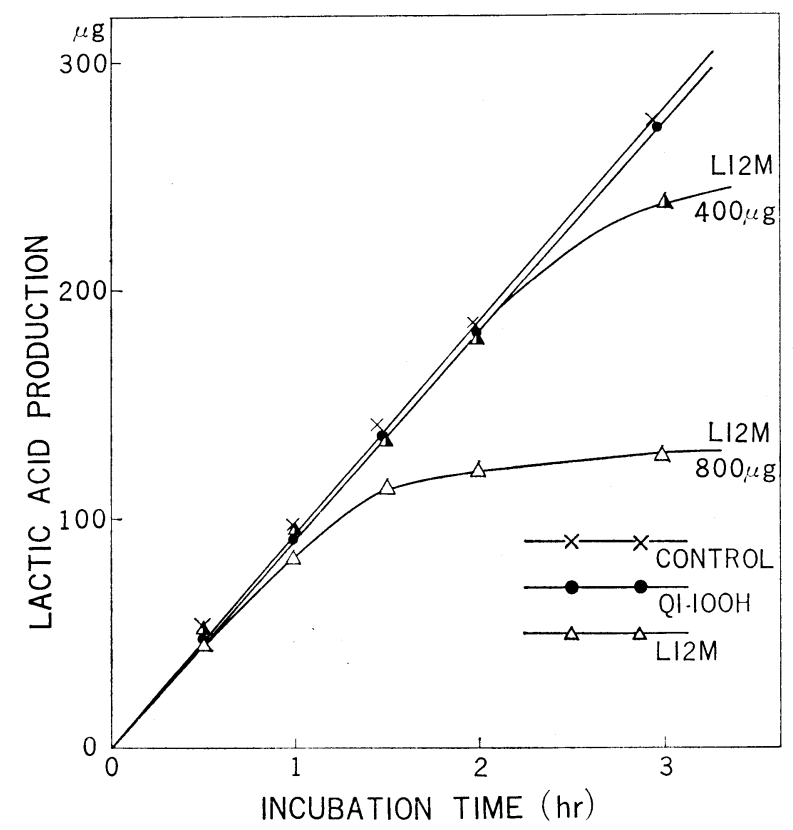

Fig. 7. Production of lactic acid by monocytes of rat incubated $\operatorname{LI} 2 \mathrm{M}(\triangle)$ or $\mathrm{QI}-\mathrm{IOOH}(\mathrm{O})$, and alone $(x)$. 


\section{K. KOSHI}

the lactic acid production by the monocytes without dust and with QI-100H increased linearly. In the case of the addition of $400 \mu \mathrm{g}$ of LI2M, lactic acid production dropped by the incubation for 3 hours as compared with control. In the case of the addition of $800 \mu \mathrm{g}$ of LI2M, lactic acid production stopped after incubation for 1.5 hours. The amounts of nucleotide in the monocytes were shown in Table 2 . In $400 \mu \mathrm{g}$ added group, the amounts of acid-soluble nucleotide dropped below $30 \%$ to control after incubation for 3 hours. In the case of $800 \mu \mathrm{g}$ added group, the amounts of nucleotide decreased also below $30 \%$ of control values after ncub ation for 1.5 hours.

Table 2. The percentage of the amounts of acid-soluble nucleotide of monocyte by the addition of LI2M to that of controls.

\begin{tabular}{|c|c|c|c|c|c|}
\hline $\begin{array}{c}\text { Incubation } \\
\text { hrs. }\end{array}$ & 0.5 & 1 & 1.5 & 2 & 3 \\
\hline $400^{\mu g}$ & $80.0^{\%}$ & 64.0 & 52.0 & 42.0 & 27.5 \\
\hline 800 & 67.0 & 57.0 & 27.5 & 25.0 & 12.5 \\
\hline
\end{tabular}

\section{Discussion}

The toxicities of various dusts to monocytes were generally8), 9) expressed by the amount of dust per culture required to depress the TTC reducing capacity using glucose as substrate o 50\% of control and as shown in Table 1, significant change of the tetrazolium reducing capacity was produced by LI2M when glucose was used as substrat. Although the pathway by which the tetrazolium is reduced by the monocytes is obscure, this pathway should pass the glycolytic system and terminal electron transport system of monocytes, as the TTC reducing capacity of monocytes is almost completely inhibited by the addition of $10^{-3} \mathrm{M}$ odoacetic acid, $10^{-3} \mathrm{M} \mathrm{NaF}, 10^{-3} \mathrm{M} \mathrm{KCN}$. Futhermore, in the previous paper ${ }^{1)}$ the amounts of acid soluble nucleotide, especially adenine nucleotide, were reduced remarkably and rapidly by the addition of LI2M dusts and this decrease seems to be correlated with that of the TTC reducing capacity, whereas, the succinate-and DPNH-TTC reducing capacity of monocytes was slightly inhibited by LI2M in comparision with glucose-TTC reducing capacity. From the above explained results, the author hypothesized that injured process of monocytes by LI2M was evoked from the inhibition of glycolysis which was caused by the decrease of adenine nucleotide. But, from the present reports this hypothesis is denied. For the relation between the decrease of acid-soluble nucleotide or the decrease of TTC reducing capacity of monocytes and the decrease of lactic acid production is not linear. When the acid-soluble nucleotide is reduced below 30\%, the production of lactic acid and the consumption of glucose decrease. So, it is assumed that the amounts of adenine nucleotide in monocytes are in excess of the doses needed to glycolytic activity.

From above results following conclusions are conducted, 1) TTC reducing capacity of monocytes are not directly correlated to the glycolytic and succinoxidase activity, 2) the first 


\section{EFFECT OF QUARTZ ON CELLULAR METABOLISM}

step of the injured action of LI2M of monocytes is not an attack to the glycolytic and respiratory system.

The drop of the lactic acid production is used as the mark of injured action by dust by Kessel ${ }^{19)}$; however it was assumed that the injured process in early stadium could not be caught by the drop of lactic acid production.

\section{ACKnowledgement}

The writer wishes to express her sincere thanks to Dr. H. Sakabe for his guidance and helpful advice during the course of this investigation. Thanks are also due to Miss M. Yasukawa for skilled techinical assistance and due to Mr. A. Hamada for supply of the quartz particles.

\section{REFERENCES}

1) Koshi, K. (1964). Ind. Health, 2, 19.

2) Sakabe, H., Kawai, K., Koshi, K., Soda, R., Hamada, A., Shimazu, M. and Hayashi, H. (1960). Bull. Nat. Inst. Ind. Health, 4, 1.

3) Marks, J. and James, D. M. (1959). J. Pathol. Bacteriol., 77, 401.

4) Brown, A. H. (1946). Arch. Biochem., 11, 269.

5) Barker, S. B. and Summerson, W. H. (1941). J. Biol. Chem., 138. 535.

6) Schneider, W. C. and Potter, V. R. (1943). J. Biol. Chem., 140. 213.

7) Koshi, K. (1963). Ind. Health, 1, 28.

8) Koshi, K., Hayashi, H., Hamada, A. and Sakabe, H. (1961). Bull. Nat. Inst. Ind. Health, 6, 10 .

9) Marks, J. and Nagelschmidt, G. (1959). A. M. A. Arch. Ind. Health, 20, 383.

10) Kessel, R. W. I., Monaco, L. and Marchisio, M. A. (1963). Brit. J. Exptl. Pathol., 44, 351. 